\title{
Carcinoma of the oesophagus associated with membrano-proliferative glomerulonephritis
}

\author{
J. F. WALKER \\ M.B., M.R.C.P.I. \\ S. O'NEILL \\ M.R.C.P.I., M.R.C.P.(U.K.) \\ E. CAMPBell \\ O. BROWNE \\ L.R.C.P. \& S.I., D.Ch. \\ G. DOYLE \\ M.D., F.R.C.Path. \\ M. CARMody \\ M.D., F.R.C.P.I.
W. F. O'DWYER
M.D., F.R.C.P.I.

Department of Renal Medicine and Transplantation, The Charitable Infirmary, Jervis Street, Dublin 1

\begin{abstract}
Summary
Nephrotic syndrome has been observed in association with different types of neoplasia. This appears to be the first report of the occurrence of the nephrotic syndrome due to membrano proliferative glomerulonephritis in association with carcinoma of the oesophagus. Although proteinuria was present before excision of the tumour, the nephrotic phase occurred subsequently. Eventually it disappeared leaving the patient with a clear urine and biochemical and histological improvement of the renal lesion (including immunofluorescent and electronmicroscopy studies). Possible mechanisms responsible for the nephrotic syndrome in this case are discussed.
\end{abstract}

\section{Introduction}

Nephropathy associated with extra-renal neoplasms has been well documented (Lee, Yamauchi and Hopper, 1966; Loughridge and Lewis, 1971; Higgins, Randall and Still, 1974; Eagen and Lewis, 1977). More recently, glomerular lesions associated with renal malignancy have been described (Ozawa et al., 1975; Cosby et al., 1974; Eagen and Lewis, 1977). A variety of morphological glomerular lesions have been associated with tumours. Membranous nephropathy, membrano-proliferative glomerulonephritis, and lipoid nephrosis have been identified as the major renal histological pattern in these reports.

The authors report for the first time, the association of carcinoma of the oesophagus and nephrotic syndrome as a result of membrano-proliferative glomerulonephritis, which presented following excision of the tumour, and resolved spontaneously. The patient remains well with no evidence of recurrence or metastases, maintaining normal renal function without proteinuria 24 months post operatively.

\section{Case report}

A 59-year-old female was referred from another hospital with a 5-week history of bilateral lofer limb oedema. An oesophagectomy had been formed 7 weeks previously for well differenticted squamous carcinoma of the middle third of the oesophagus. Urinalysis revealed $0 \cdot 14 \mathrm{~g}$ protein wi重 RBCs and granular casts at the time of operation

Physical examination was unremarkable except for bilateral lower limb oedema. Pertinent laboratory investigations included a haemoglobin $12.6 \mathrm{~g} / \mathrm{f}$. Haematocrit $45 \%$, white cell count $7 \cdot 1 \times 10 \mathrm{~g} / \mathrm{l}$ with a normal differential, serum urea $7 \mathrm{mmol} / \mathrm{l}$, serum creatinine $80 \mu \mathrm{mol}$, serum proteins $51 \mathrm{~g} / 1$, seru albumin $21 \mathrm{~g} / \mathrm{l}$, serum cholesterol $10.36 \mathrm{mmol} / 1$. 24-hr urine collection demonstrated a total prote excretion of $10.64 \mathrm{~g}$ and a creatinine clearance $1.84 \mathrm{ml} / \mathrm{s}$. Microscopic examination revealed $\rightrightarrows$ RBCs/HPF with granular and cellular casts. The serum sodium was $136 \mathrm{mmol} / \mathrm{l}$, potassium $4 \mathrm{mmol} /$, chloride $94 \mathrm{mmol} / \mathrm{l}$ and bicarbonate $26 \mathrm{mmol}$. Serological studies including serum complement and anti-nuclear factor were negative.

A percutaneous renal biopsy was performed and the tissue was examined by light microscopy, immunofluorescent staining and electron micro scopy. The first biopsy (Figs 1,2 and 3) revealed lesion characteristic of membrano-proliferative gl\$ merulonephritis with marked mesangial cell prog liferation, mesangial and subendothelial deposits and mesangial interposition to form splits of duplications of the basement membrane. Immuno fluorescence showed the presence of granular ang 


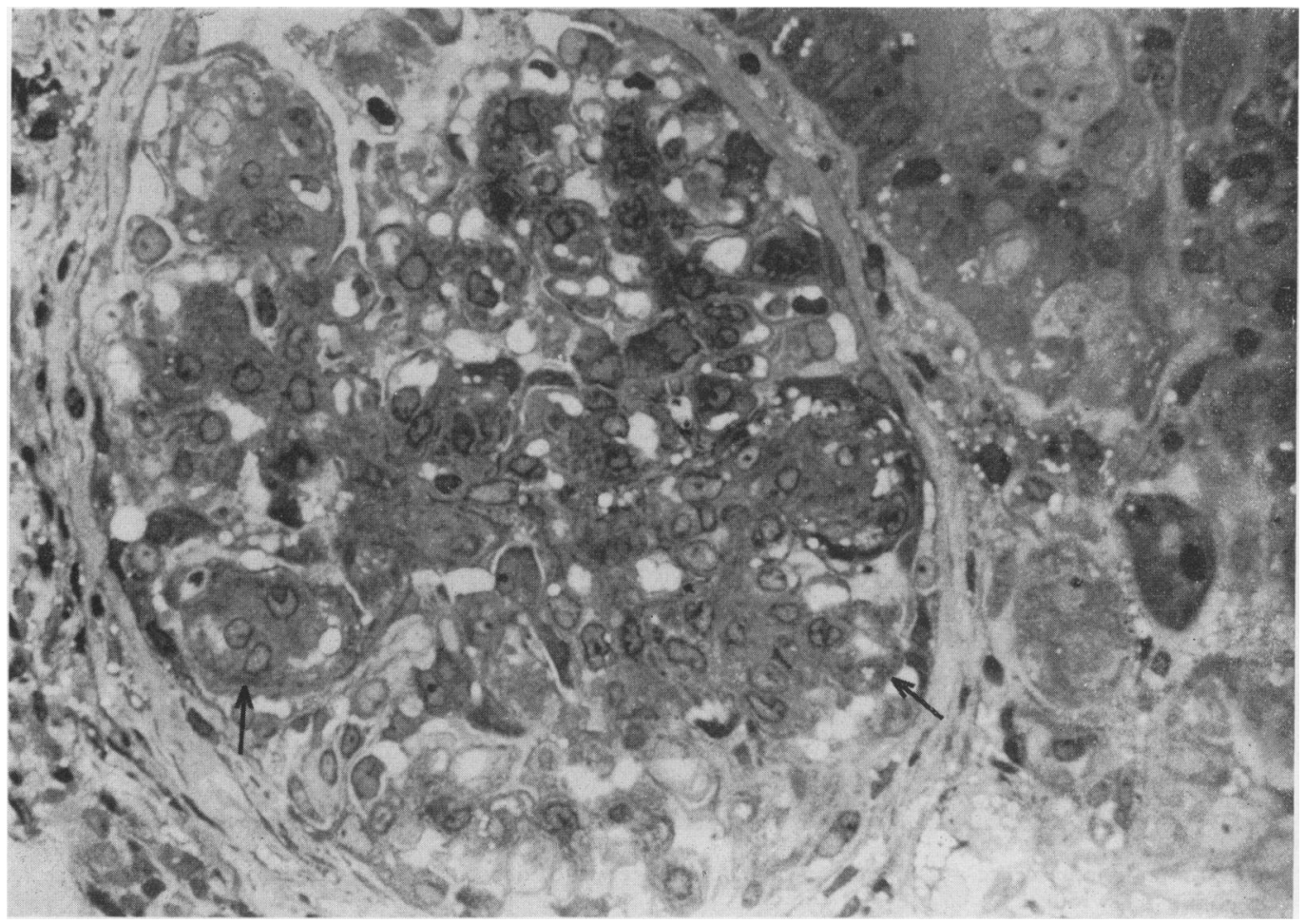

FIG. 1. A representative glomerulus from the first biopsy showing a marked increase in mesangial cells and matrix. There is an obvious decrease in capillary loop patency with the presence of subendothelial deposits $(\uparrow)$ and mesangial interposition which is seen to better advantage in Fig. 2. (One- $\mu \mathrm{m}$ Epon section stained with Toluidine blue, original mag. $\times 200)$.

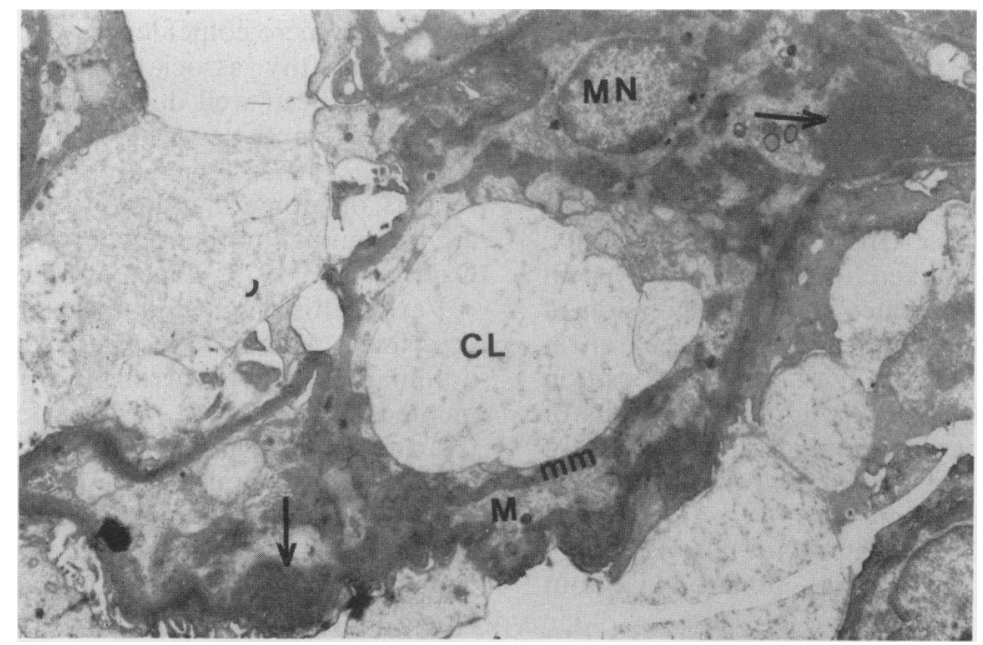

Fig. 2. Electron micrograph of a glomerular capillary loop showing electron dense deposits $(\uparrow)$ on the inner aspect of the basement membrane and in the mesangium. The mesangial cell cytoplasm (M) and mesangial matrix (mm) is seen to extend peripherally for part of the circumference of the capillary to form a characteristic duplication of the basement membrane. (Original mag. $\times 2500$ ). CL, capillary lumen; MN, mesangial cell nucleus. 


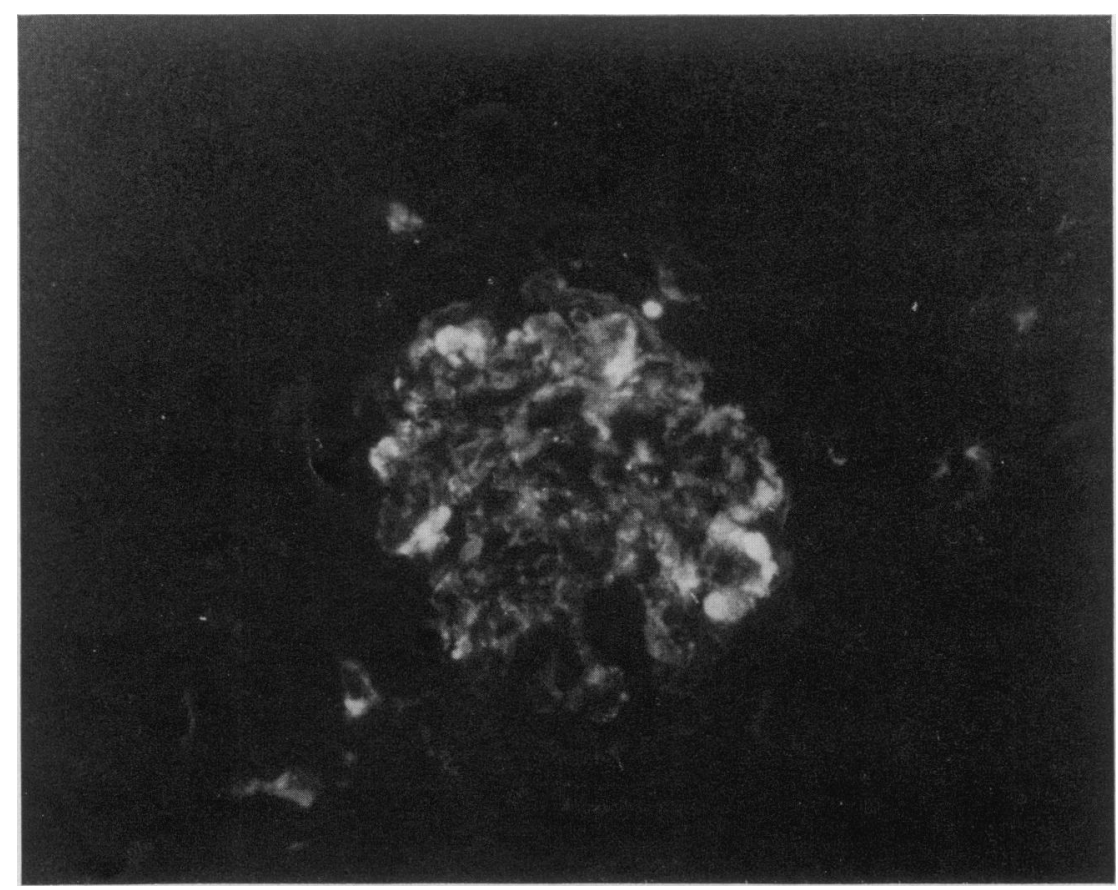

FIG. 3. Immunofluorescence-first biopsy. Granular and aggregated deposits of IgM on the basement membrane. (Original mag. $\times 150)$.

aggregated deposits of $\operatorname{IgM}$ and complement $\left(\mathrm{C}_{3}\right)$ on the basement membrane and mesangial deposits of complement. All glomeruli were equally involved.

The patient was treated with high protein, low salt diet and frusemide $40 \mathrm{mg} /$ day for 3 weeks. Three months later she was readmitted for reevaluation of her renal status. She was on no medication. Physical examination was unremarkable. Laboratory values disclosed the following: serum creatinine $53 \mu \mathrm{mol} / \mathrm{l}$; urine microscopic examination revealed $5 \mathrm{RBCs} / \mathrm{HPF}$ with no casts; 24-hr urinary protein excretion was $1 \cdot 1 \mathrm{~g}$. Repeat renal biopsy (Fig. 4) revealed marked regression of mesangial cellularity with disappearance ultrastructurally of all evidence of mesangial interposition in the capillary walls. Isolated granular deposits of IgM and complement were present on the basement membrane in 4 of 5 glomeruli. No deposits were seen in the remaining glomerulus.

She remains well 2 years later with no evidence of metastases, and normal renal function without proteinuria.

\section{Discussion}

Proteinuria, often of sufficient magnitude to cause the nephrotic syndrome, is a recognized systemic manifestation of neoplastic disease Lee et al. (1966) were the first to emphasize the high incidence (11\%) of carcinoma in the adult nephrot population. The frequency of renal disease observed with malignancy suggests that this association is more than mere coincidence.

Nephropathy associated with extra-renal neoplasia has been well documented (Lee et al., 196\%; Loughridge and Lewis, 1971; Higgins et al., 1974 Row et al., 1975; Eagen and Lewis, 1977), although reports of glomerular lesion with renal neoplasmis are becoming more frequent (Cosby et al., 1974, Ozawa et al., 1975; Eagen and Lewis, 1977).

Various histological glomerular lesions have been described. Membranous nephropathy is the pre dominant lesion occurring in $70 \%$ of cases doct mented (Eagen et al., 1977). Membrano-prolifer tive and lipoid nephrosis occur with less frequenci Renal vein thrombosis, amyloid and glomerulaP invasion of tumour must be considered in thle aetiology of the paraneoplastic proteinuria. THE neoplasms may be solid (Cantrell, 1969; Costanza et al., 1973; Couser et al., 1974; Eagen and Lewis 1977), occasionally myeloproliferative disordess (Lowry, Munzenrider and Lynch, 1971; Row et 1975; Eagen and Lewis, 1977), and rarely benigit (Cosby et al., 1974). 


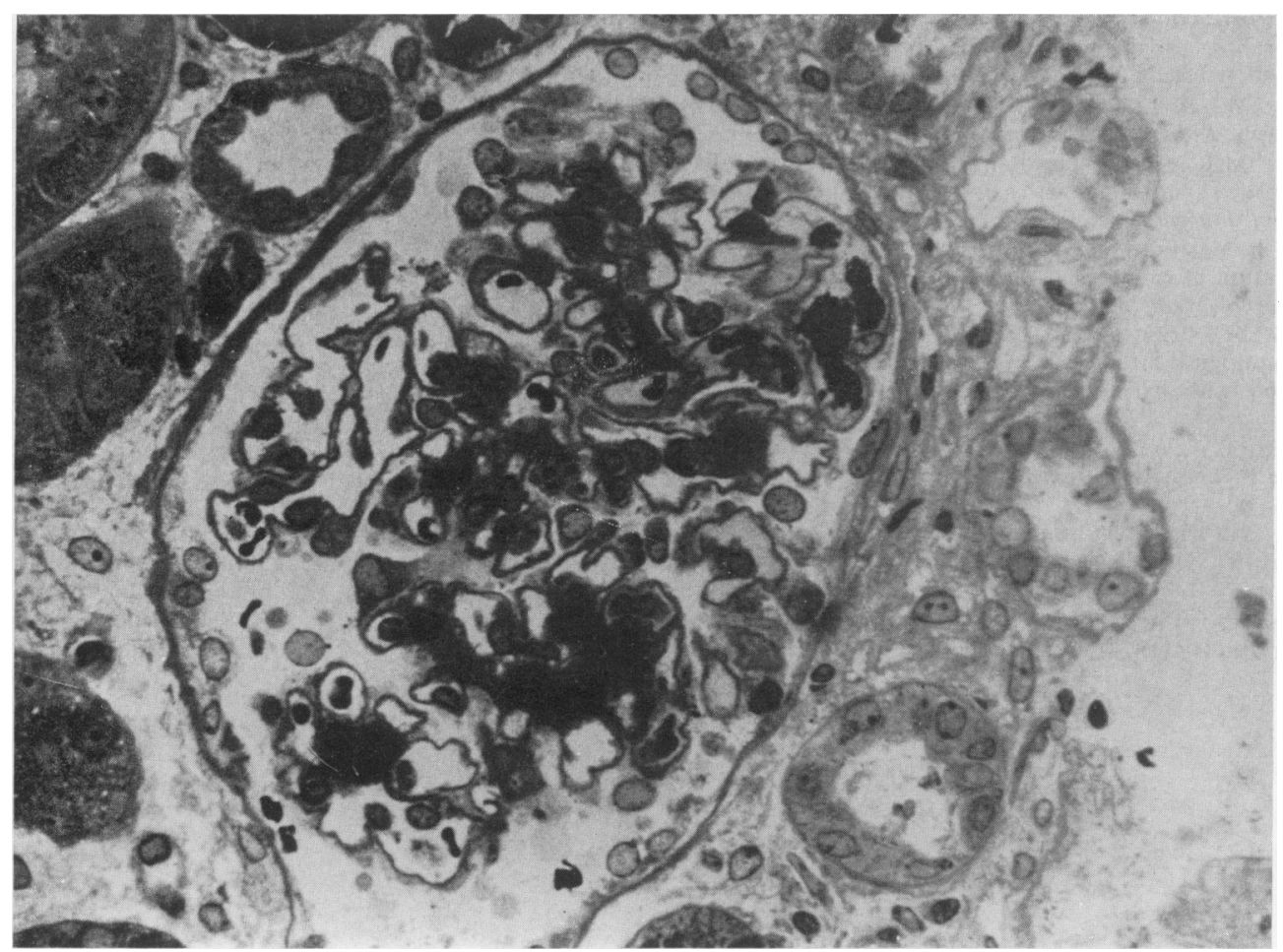

Fig. 4. A glomerulus from second biopsy showing some residual mesangial hypercellularity and matrix increase. There is disappearance of the mesangial interposition seen in the first biopsy. (One- $\mu \mathrm{m}$ Epon section stained with Toluidine blue, original mag. $\times 200$ ).

The aetiology of the glomerular lesion is thought to be immune complex in origin as a result of antibody production to (1) tumour-associated antigens, (2) re-expressed fetal antigens, (3) viral antigens or (4) autologous non-tumour antigens. Evidence supporting this is the presence of circulating immune complexes in various forms of neoplasia (Rossen et al., 1976). Tumour-associated antigens have been found in glomerular deposits of tumour-related nephropathy (Lewis, Loughridge and Phillips, 1971; Couser et al., 1974). Costanza et al. (1973) found a tumour-expressed fetal antigen, and carcinoma embryonic antigen in glomerular immune deposits of a patient with colonic adenocarcinoma. Epstein-Barr virus antibody (Oldstone, 1974) and oncornavirus antigen (Sutherland and Mardiney, 1973) have been found in glomerular deposits. The presence of a high incidence of nonorgan-specific antibody suggests the final possibility of auto-immunity against self antigens. The improvement in the subsequent renal biopsy on light microscopy with a marked decrease in immune complexes by immunofluorescence would support the view that immune complexes were the aetio- logical agents of the lesion in this patient. However, the underlying antigen remains unclear.

Although successful removal of a tumour may result in complete remission of proteinuria (Cantrell, 1969), the survival after clinical recognition of the neoplasia is generally 3 months (Eagen and Lewis, 1977).

The importance of the association between rieoplasia and glomerulonephritis is stressed especially in the adult nephrotic patient with an underlying membranous nephropathy in whom early diagnosis and treatment of a neoplasia may result in a better prognosis.

\section{References}

Cantrell, E.G. (1969) Nephrotic syndrome cured by removal of gastric carcinoma. British Medical Journal, 2, 739 .

Cosby, Rd., Yamauchi, H., Lee, J.C. \& Hopper Jr, J. (1974) Tumor-related renal lesion reversed followed tumor excision. Clinical Research, 22, 136A.

Costanza, M.E., Piun, V., Schwartz, R.S. \& Nathamson, L. (1973) Carcinoembryonic antigen-antibody complexes in a patient with colonic carcinoma and nephrotic syndrome. New England Journal of Medicine, 289, 520.

Couser, W.G., Wagorfeld, J.B., Spargo, B.H. \& Lewis, 
E.J. (1974) Glomerular deposition of tumor antigen in membranous nephropathy associated with colonic carcinoma. American Journal of Medicine, 57, 962.

EAGEN, J.W. \& LeWIS, E.J. (1977) Glomerulopathies of neoplasia. Kidney International, 11, 297.

Higgins, M.R., Randall, R.E. \& Still, W.J.S. (1974) Nephrotic syndrome with oat-cell carcinoma. British Medical Journal, 3, 450.

Lee, J.C., Yamauchi, H. \& Hopper Jr, J. (1966) The association of cancer and the nephrotic syndrome. Annals of Internal Medicine, 64, 41.

Lewis, M.G., Loughridge, L.W. \& Phillips, T.M. (1971) Immunological studies in the nephrotic syndrome associated with extrarenal malignant diseases. Lancet, ii, 134.

Loughridge, L.W. \& Lewis, M.G. (1971) Nephrotic syndrome in malignant disease of non-renal origin. Lancet, i, 256.

LoWry, W.S., Munzenrider, J.E. \& LyNCH, O.A. (1971) Nephrotic syndrome in Hodgkin's disease. Lancet, i, 1127.

Oldstone, M.B.A., Theofilopoulos, A.N., Gunven, P. \& Vilein, G. (1974) Immune complexes associated with neoplasia: presence of Epstein-Barr virus antigen antibody complexes in Burkitt's lymphoma. Intervirology, 4, 292. Ozawa, T., Pluss, Rd., Lacker, J., Boedecker, E., Guggkiheim, S., Hammon, D.W. \& McIntosh, R. (1975) Endgenous immune complex nephropathy associated wiph malignancy studies on the nature and immunopathogegic significance of glomerular bound antigen and antibofy, isolation and characterization of tumor specific antigen and antibody and circulating immune complexes. Quarte $\mathrm{D} y$ Journal of Medicine, 44, 523.

Rossen, R.D., Reisberg, M.A., Hersh, E.M. \& Guttermain, J.U. (1976) Measurement of soluble immune complexes: a guide to profusion in cancer patients. Clinical Resear 24, 462A.

Row, P.G., Cameron, J.S., Turner, D.R., Evans, D. $\overrightarrow{\mathrm{J}}$ White, R.H.R., OGg, C.S., Chantler, C. \& Brown, C@. (1975) Membranous nephropathy: long-term follow-opp and association with neoplasia. Quarterly Journal $f$ Medicine, 44, 207.

Sutherland, J.C. \& MARdiney, M.R. (1973) Immưur complex disease in the kidneys of lymphoma-leukengia related patients: in the presence of an oncornavirusrelated antigen. Journal of the National Cancer Institute 50, 633. 